\title{
JOBMIX BETON MENGUNAKAN PASIR LUMAJANG DAN PENAMBAHAN ADDITIVE MASTERPOZZOLITH ${ }^{\circledR}$ 402R
}

\author{
Ahmad Ridwan, Sigit Winarko, Eko Siswanto \\ ${ }^{1}$ Staf Pengajar Program Studi Teknik Sipil Fakultas Teknik Universitas Kadiri \\ Program Studi Teknik Sipil Fakultas Teknik Universitas Kadiri \\ Email: ahmad_ridwan@unik-kediri.ac.id
}

\begin{abstract}
Concrete is an important element in a construction. The strength of the concrete is determined by the quality of the concrete. So that the mixture used must meet the standards, by using selected materials and adding other substances, it will produce a higher quality than SNI. Masterpozzolith ${ }^{\circledR} 402 R$ additive is a mixture of concrete material that serves as a bonding enhancer on concrete, this material will react with cement and water so that when the element is fused it will produce a better bond between coarse and fine aggregates. In this study concrete will use lumajang sand and add the masterpozzolith ${ }^{\circledR} 402 R$ additive as an additional material to achieve the desired high quality. with a concrete job mix using the $K-200$, it is expected to produce concrete with a quality above the specified target. The results of this study can include more than the targets that have been determined, with planning to use mutubeton $K-200$ the concrete produced can reach K-222, so the method is quite good when applied in construction.
\end{abstract}

Keywords: concrete, additive, masterpozzolith ${ }^{\circledR} 402 R$

\section{PENDAHULUAN}

Beton merupakan salah satu unsur penting sebagai elemen pembentuk struktur yang banyak digunakan pada saat ini, hal ini dikarenakan beton mempunyai kelebihan antara lain : (1) Memiliki kekuatan yang tinggi. (2) Dapat di bentuk sesuai ukuran yang di kehendaki. (3) Perawatan yang ekonomis. (4) Mudah digunakan daripada bahan kontruksi yang lain. (5) Awet dan tahan terhadap cuaca serta api.

Bahan pokok penyusun beton antara lain semen, air, pasir (agregat halus) dan batu pecah (agregat kasar). Bahan air dan semen disatukan akan membentuk pasta semen, dan berfungsi sebagai bahan pengikat. Sedangkan pasir (agregat halus) dan batu pecah (agregat kasar) berfungsi sebagai bahan pengisi. Saat ini telah dilakukan berbagai inovasi untuk mencari material alternatif untuk pembuatan beton. Salah satunya dengan mencari agregat halus yang efisien dan memiliki kuat tekan yang optimum.

Dimana dalam penelitian ini menggunakan agregat halus yaitu pasir
Lumajang dan penambahan bahan additive masterpozzolith ${ }^{\circledR} 402 \mathrm{R}$. Dimana dalam pemanfaatannya diharapkan dapat menemukan hasil kuat tekan beton yang baik. Dengan adanya penelitian ini, penulis diharapkan dapat memberikan sumbangsih penelitian yang bermanfaat bagi masyarakat. Kemudian dapat diterapkan dan diteliti lagi lebih lanjut. Keuntungan pemakaian beton sebagai bahan bangunan antara lain: bahan ini dapat dibentuk sesuai dengan keinginan perencana di lokasi pekerjaan, bahan-bahan pembentuk relatif tersedia dan pembuatan beton dapat dilakukan oleh para pekerja.

Hal-hal inilah yang menyebabkan beton sebagai bahan bangunan tetap menjadi pilihan utama para perencana dalam mendisain dan merencanakan bangunan-bangunan teknik sipil. Beton mempunyai kelebihan kuat tekan yang tinggi, dapat dibentuk sesuai dengan apa yang kita inginkan, mudah dalam perawatannya dan dapat digunakan untuk konstruksi ringan maupun berat. 


\section{DASAR TEORI \\ Material \\ Agregat kasar}

Batu kali adalah bongkahan batu yang pada umumnya memiliki ukuran tidak beraturan yang didapatkan dari sungai ataupun gunung. Batu kali merupakan salah satu bahan bangunan yang penting untuk membangun rumah/bangunan, yaitu sebagai pembuatan pondasi rumah/ bangunan. Batu kali dipasang bersama mortar (campuran semen, pasir, dan air) sebagai konstruksi awal pembuatan dinding rumah.

Batu kali juga merupakan bahan bangunan yang tahan terhadap kondisi lingkungan seperti hujan dan panas, sehinggasampai saat ini penggunaannya sebagai agregat kasar pada beton masih belum tergantikan dengan bahan buatan. Batu kali merupakan bahan utama dalam jobmix beton. Kami menggunakan batu kali yang tertahan pada ayakan $19,1 \mathrm{~mm}, 12,7 \mathrm{~mm}$ dan $9,52 \mathrm{~mm}$ memiliki berat jenis $1800 \mathrm{~kg} / \mathrm{m}^{3}$.

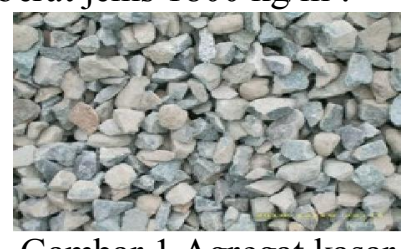

\section{Semen}

Gambar 1 Agregat kasar

Semen dalam hal ini berfungsi sebagai zat perekat atau pengikat material penyusun struktur Beton. Dari beberapa type Semen, kami menggunakan jenis Semen Portland Type I. Mengingat jenis dari semen portland type I mudah dijangkau untuk mendapatkannya. Jenis semen seperti ini biasa dipergunakan untuk konstruksi bangunan umum yang tidak memerlukan persyaratan khusus dalam hidrasi panas dan kekuatan tekan awal. Namun untuk kemampuan ikat lebih daripada Beton ringan, kami mempergunakan zat bantu (Additive) Masterpozzolith $^{\circledR} 402 R$.

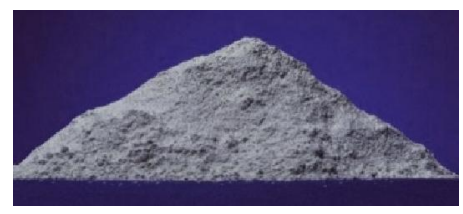

\section{Pasir}

Gambar 2 Semen

Pasir merupakan material granular alami yang belum terkonsolidasi. Pasir terdiri dari butiran -butiran yang berukuran dari 1/16 - 2 mm. Butiran pasir bisa berupa mineral tunggal, fragmen batuan atau biogenik.

Pasir terbentuk karena adanya proses pelapukan fisik dan kimia pada batuan. Proses pelapukan ini biasanya dipelajari secara terpisah, tetapi pada kenyataannya kedua proses ini biasanya berjalan beriringan karena keduanya cenderung saling mendukung dalam proses pelapukan.

Pasir besi/ lumajang adalah sejenis pasir dengan konsentrasi besi yang signifikan. Hal ini biasanya berwarna abu-abu gelap atau berwarna kehitaman. Pasir ini terdiri dari magnetit, $\mathrm{Fe} 3 \mathrm{O} 4$, dan juga mengandung sejumlah kecil titanium, silika, mangan, kalsium dan vanadium.

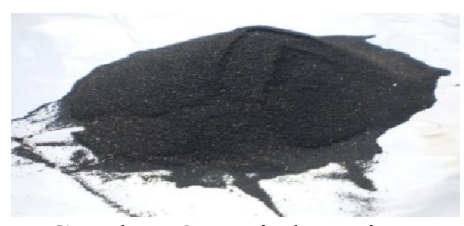

Gambar 3 pasir lumajang

Air

Air adalah substansi kimia dengan rumus kimia H2O. Suatu molekul air tersusun atas 2 atom hidrogen yang terikat secara kovalen pada satu atom Oksigen. Air bersifat tidak berwarna, tidak berasa dan tidak berbau pada kondisi standar, yaitu pada tekanan $100 \mathrm{kPa}(1$ bar) hingga pada temperatur $0^{\circ} \mathrm{C}$. Zat kimia ini merupakan sebuah zat pelarut yang penting, memiliki kemampuan untuk melarutkan zat kimia lainya terkhusus untuk membantu proses pelarutan reaksi semen pada proses mixing Beton ringan.

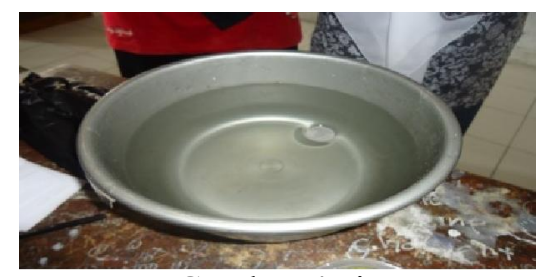

Gambar 4 air

Additive

Additive adalah suatu zat kimia yang berfungsi untuk membantu kelangsungan proses pembuatan mix design yang kita inginkan. Pada additive yang kami pakai dalam proses pembuatan mix design ini adalah jenis additive MasterPozzolith ${ }^{\circledR}$ 402R yang berguna untuk meminimkan jumlah air dalam membuat spesi Beton dengan tambahan daya ikat yang dihasilkan. 


\section{$\square-$ BASF}

We create chemistry

\section{MasterPozzolith ${ }^{\circledR}$ 402R}

\section{Set retarding and water reducing concrete admixture}

\section{DESCRIPTION}

MasterPozzolith ${ }^{\circledR}$ 402R is a ready-to-use, liquid admixture for producing quality concrete with consistent performance.

It reduces the quantity of mixing water required to produce concrete of a given workability with greater economy for a given strength. The retarding nature of the admixture also aids placing and finishing of concrete.

MasterPozzolith ${ }^{\circledR}$ 402R meets ASTM
C494/C494M - 08 a Type B (Retarding) and
Type D (water-reducing and retarding)
admixtures. It does not contain chloride- based
ingredients and will not initiate or promote
corrosion of reinforcing steel in concrete.
FIELDS OF APPLICATION

MasterPozzolith $^{\circledR}$ 402R RT admixture is recommended for use in all types of concrete where moderate to extended retardation of set and improved performance are desired. The admixture improves workability of pumped concrete, shotcrete (wet mix) and conventionally placed concrete.

MasterPozzolith $^{\circledast}$ 402R can be used with high content of manufactured sand and with air entraining admixtures approved under ASTM When used in conjunction with another admixture, each admixture must be dispensed separately into the mix. By itself, Master Pozzolith $^{\oplus}$ 402R admixture does not entrain air.

Concrete produced with MasterPozzolith ${ }^{\oplus}$ 402R admixture will have appreciable strength development after initial set occurs. If retardation is within the normal ASTM C $494 / C 494 M-08 a$ types B and D specifications, MasterPozzolith 402R admixture will develop higher early (24 hours) and higher ultimate strengths than plain concrete when used within the recommended dosage range and under normal, comparable curing conditions.

\section{FEATURES AND BENEFITS}

MasterPozzolith ${ }^{\circledR}$ 402R used at optimum dosage enhances the performance of concrete providing the following special qualities:

- Improved workability

- Reduced segregation
- Superior finishing characteristic

- Controlled retardation depending on the rate of addition

- Provides flexibility in scheduling of placing and finishing

- Offset effects of too early hardening during extended delays between mixing and placing.

- Helps eliminate cold joints

- Lower peak temperature and/or rate of temperature rise in mass concrete reduces thermal cracking

MasterPozzolith ${ }^{\circledR}$ 402R admixture is recommended for use at the rate of $200-400 \mathrm{ml}$ per $100 \mathrm{~kg}$ of cementitious content for most concrete mixes using typical concrete ingredients. Because of variations in job conditions and concrete materials, dosage rates other than recommended amounts may be required. In such cases, contact your local Master Builders Solutions representatives.

PACKAGING

MasterPozzolith ${ }^{\circledR}$ 402R is available in $205 \mathrm{~L}$ drum, IBC 1,000 L and in bulk delivery.

\section{SHELF LIFE}

MasterPozzolith ${ }^{(1)}$ 402R admixture has a minimum shelf life of 12 months. Depending on storage conditions, the shelf life may be greater than stated. Please contact you Master Builders Solutions representative regarding suitability for use and dosage recommendations if the shelf life of MasterPozzolith $^{(3)}$ 402R admixture has been exceeded.

\section{PRECAUTIONS}

Health: MasterPozzolith ${ }^{\circledR}$ 402R does not contain any hazardous substances requiring labelling. It is safe for use with standard precautions followed in the construction industry, such as use of hand gloves, safety goggles, etc. For detailed Health, Safety and Environmental recommendations, please consult and follow a instructions in the product Material Safety Data Sheet.

MASTER \BUILDERS 


\section{- BASF}

We create chemistry

\section{MasterPozzolith ${ }^{\circledR}$ 402R}

STATEMENT OF The technical information and application advice given in this BASF publication are based on the present state of RESPONSIBILITY our best scientific and practical knowledge. As the information herein is of a general nature, no assumption can be made as to a product's suitability for a particular use or application and no warranty as to its accuracy, reliability or
completeness either expressed or implied is given other than those required by law. The user is responsible for checking the suitability of products for their intended use.

Field service where provided does not constitute supervisory responsibility. Suggestions made by BASF either orally or in writing may be followed, modified or rejected by the owner, engineer or contractor since they, and not

NOTE BASF, are responsible for carrying out pracedures appropriate to a specific application.

PT BASF Indonesia

DBS Bank Tower 27 th Floo

Ciputra World 1 Jakarta

J.. Prof. Dr. Satrio Kav. 3-5

Jl. Prof. Dr. Sat
Jakarta 12940

Jakarta 12940

Website: www.master-builders-solutions.basf.co.id 


\section{METODE PENELITIAN}

Metode langkah kerja untuk2 sampel antara lain :

a. Proses pengambilan pasir (agregat halus) dengan mengunakanayakantertahan1,19 mmdan0,59 $\mathrm{mm}$.

b. Pengovenan Pasir guna pengambilan bahan sesuai berat kering sebanyak $7,32896 \mathrm{~kg}$

c. Menyediakan Koral dengan mengunakanayakantertahan 19,1 mm, 12,7 mm dan 9,52 mm dan sebanyak $6,09425 \mathrm{~kg}$

d. Menyediakan Semen Portland type I sebanyak $2,86875 \mathrm{~kg}$

e. Menyediakan Air guna proses pelarutan dan pencampuran sebanyak $1,591775 \mathrm{~kg}$

f. Menyediakan larutan Additive MasterPozzolith ${ }^{\circledR} 402 \mathrm{R}$ sebanyak 0,1134 $\mathrm{kg}$

g. Proses mixing menggunakan media mesin pengaduk elektrik

1) Masukan air, larutan additive MasterPozzolith $\AA_{402 R d a n}$ semen kedalam mesin pengaduk.

2) Putar mesin pengaduk selama 20 menit agar bahan perekat tercampur dengan sempurna.

3) Masukan seluruh Koral pada mesin pengaduk secara bertahap.

4) Setelah Koral dikira telah tercampur dengan campuran Air, Larutan Additive dan Semen pada 15 menit putaran Mixer, masukkan Pasir secara bertahap.

5) Setelah seluruh bahan tercampur secara sempurna, adonan di uji test slump guna mengetahui kadar air yang terkandung pada adonan segar beton ringan.

6) Jika kadar air setabil masukan adonan segar mix design beton ringan kedalam cetakan kubus dengan ukuran sisi 15 $\mathrm{cm}$ serta dalam pemasukkan adonan beton segar kedalam cetakan diharuskan untuk disertai penggetaran pada cetakan guna mengantisipasi rongga pada struktur beton.

7) Biarkan adonan Beton mengering hingga sempurna, antara 7 - 10 Hari.

8) Setelah kering, bongkar cetakan beton dan lanjutkan proses curing beton kedalam kolam selama waktu analisa 28 hari.
9) Angkat Beton dari kolam curing dan angin-anginkan Beton selama 1 hari guna proses pengeringan.

10) Proses test uji kuat tekan beton.

\section{HASIL DAN PEMBAHASAN}

Setelah melakukan percobaan mixing beton ringan dengan menggunaklan material sebagai berikut :

1. Air $=1,591775 \mathrm{~kg}$

2. Zat Additive MasterPozzolith $\AA 402 \mathrm{R}=$ $0,1134 \quad \mathrm{~kg}$

3. Semen Portland Type $I=2,86875 \mathrm{~kg}$

4. Pasir Lumajang $=7,32896 \mathrm{~kg}$

5. Koral / Agregat Kasar $=6,09425 \mathrm{~kg}$

Struktur beton ringan siap untuk di Test dan didapati hasil benda uji beton ringan sebagai berikut:

1. Berat bersih :
a. Beton I
$: 7,8 \mathrm{Kg}$
b. Beton II $: 8 \quad \mathrm{Kg}$

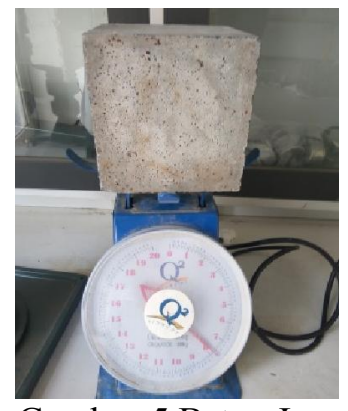

Gambar 5 Beton I

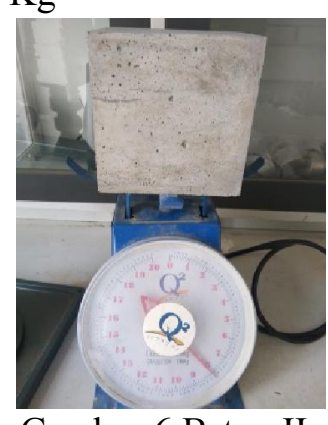

Gambar 6 Beton II
2. Kuat tekan :
a. Beton I : 222,22 Ton
b. Beton II : 222,22 Ton

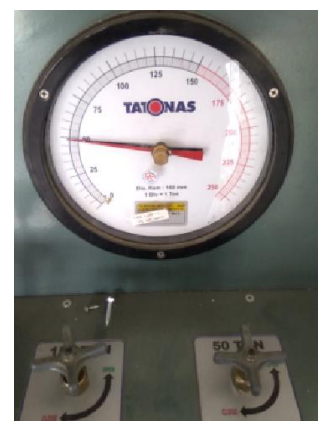

Gambar 7 Hasil tes kuat tekan beton I 


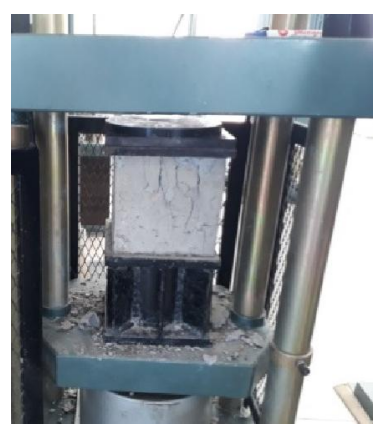

Gambar 8. Hasil tes kuat tekan beton II

3. Berat Volume Beton :

a. Beton I : 0,0078/0,003375= $2,37 \mathrm{ton} / \mathrm{m}^{3}$

b. beton II : $0,008 / 0,003375=$ $2,31 \mathrm{ton} / \mathrm{m}^{3}$

\section{KESIMPULAN}

Berdasarkan hasil penelitian yang telah dilakukan dan analisa secara keseluruhan, mulai dari pengujian bahan material beton hingga pengujian tes kuat tekan beton, maka dapat ditarik kesimpulkan sebagai berikut :

1. Beton mengalami peningkatan kuat tekan saat pengujian kuat tekan pada umur beton 28 hari yang di perencanaan job mix k-200 saat di tes tekan mencapai k-222 jadi peningkatan mencapai $11 \%$.

2. Berat jenis beton lebih ringan 0,03 0,09 ton $/ \mathrm{m}^{3}$ dibanding beton normal.

\section{REFERENSI}

Istimawan Dipohusodo, 1994, STRUKTUR BETON BERTULANG, Gramedia PustakaUmum, Jakarta.

KardiyonoTjokrodimuljo, 1992, TEKNOLOGI BETON, Jurusan Teknik Sipil, FakultasTeknik, UGM, Yogyakarta.

Badan Standardisasi Nasional. 2000. Tata Cara Pembuatan Rencana Campuran Untuk Beton Normal. SNI 03-28342000

Tjokrodimulyo, Kardiyono. 1995. Teknologi Beton. Buku Ajar Jurusan Teknik Sipil Fakultas Teknik Universitas UGM. Yogyakarta.

Badan Standardisasi Nasional. 2008. Cara Uji Keausan Dengan Mesin Abrasi Los Angeles. SNI 2417-2008.

Badan Standardisasi Nasional. 2008. Cara Uji Slump Beton SNI 2417-2008
Peraturan Beton Indonesia (PBI 1971) .Peraturan Beton Bertulang Indonesia, Jakarta: Badan penyelidik Masalah Bangunan.

Badan Standardisasi Nasional. 1990. Metode Pengujian Kuat Tekan Beton SNI 031974- 1990

Badan Standardisasi Nasional. 2008. Cara Uji Berat Jenis Dan Penyerapan Air Agregat Halus. SNI 1970-2008

Badan Standardisasi Nasional. 1990. Metode Pengujian Tentang Analisa Saringan Agregat Halus Dan Kasar. SNI 031969- 1990.

Badan Standardisasi Nasional. 2011. Cara Uji Kuat Tekan Beton Dengan Benda Uji Silinder. SNI 1974- 2011.

Badan Standardisasi Nasional. 2011. Tata Cara Pembuatan Dan Perawatan Benda Uji Beton Di Laboratorium. SNI 2493- 2011.

https://assets.master-builders-solutions.basf. com/Shared\%20Documents/PDF/Englis h\%20(Indonesia)/basf_MasterPozzolith $\% 20402 \mathrm{R}$ tds.pdf 